\title{
Cellular Shuttles: Monocytes/Macrophages Exhibit Transendothelial Transport of Nanoparticles under Physiological Flow
}

\author{
Thomas L. Moore, ${ }^{\dagger}$ Daniel Hauser, ${ }^{\dagger}$ Thomas Gruber, ${ }^{\ddagger}{ }^{\ddagger}$ Barbara Rothen-Rutishauser, ${ }^{\dagger}$

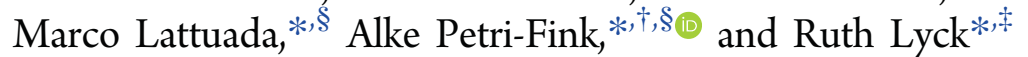 \\ ${ }^{\dagger}$ Adolphe Merkle Institute and ${ }^{\S}$ Department of Chemistry, Université de Fribourg, 1700 Fribourg, Switzerland \\ ${ }^{\ddagger}$ Theodor Kocher Institute, Universität Bern, 3000 Bern, Switzerland
}

\section{Supporting Information}

\begin{abstract}
A major hurdle in the development of biomedical nanoparticles (NP) is understanding how they interact with complex biological systems and navigate biological barriers to arrive at pathological targets. It is becoming increasingly evident that merely controlling particle physicochemical properties may not be sufficient to mediate particle biodistribution in dynamic environments. Thus, researchers are increasingly turning toward more complex but likewise more physiological in vitro systems to study particle--cell/particle-system interactions. An emerging paradigm is to utilize naturally migratory cells to act as so-called "Trojan horses" or cellular shuttles. We report here the use of monocytes/macrophages to transport NP across a confluent endothelial cell layer using a microfluidic in vitro model. With a custom-built flow chamber, we showed that physiological shear stress, when compared to low flow or static conditions, increased NP uptake by macrophages. We further provided a mathematical explanation for the effect of flow on NP uptake, namely that the physical exposure times of NP to cells is dictated by shear stress (i.e., flow rate) and results in increased particle uptake under flow. This study was extended to a multicellular, hydrodynamic in vitro model. Because monocytes are cells that naturally translocate across biological barriers, we utilized a monocyte/macrophage cell line as cellular NP transporters across an endothelial layer. In this exploratory study, we showed that monocyte/macrophage cells adhere to an endothelial layer and dynamically interact with the endothelial cells. The monocytes/macrophages took up NP and diapedesed across the endothelial layer with NP accumulating within the cellular uropod. These data illustrate that monocytes/macrophages may therefore act as active shuttles to deliver particles across endothelial barriers.
\end{abstract}

KEYWORDS: shear stress, flow, nanoparticle, cellular hitchhiker, transendothelial transport, biological barriers, Trojan horse, nanoparticle shuttle

\section{INTRODUCTION}

The implementation of nanoparticles (NP) in biomedical applications (e.g., as drug delivery vehicles, imaging contrast agents, diagnostic tools) is a hotly pursued field of research. However, the factors guiding particle localization to target sites or across biological barriers, while broadly understood to be based on particle physicochemical properties, are less easily translated from the benchtop into the clinic. ${ }^{1-3}$ That is to say, in vitro studies may describe the nanobio interactions on particle-protein or particle-cell level in static cell culture systems, but the movement of particles across biological barriers in more complex systems is less well understood.

Increasingly, researchers are looking to dynamic systems to study these fundamental $\mathrm{NP}$-cell or $\mathrm{NP}$-system interactions. For example, multicellular in vitro models may more closely mimic the influence of cell-cell communication upon NP uptake, distribution, or cell response, and thus provide a more realistic model to study particle movement through tissues. ${ }^{4,5}$ Microfluidic in vitro systems may likewise provide dynamic platforms to study particle transport and drug delivery. ${ }^{6,7}$ To this last point, microfluidic systems can be developed with increasing complexity to study the fate of NP under hydrodynamic (i.e., flow) conditions. ${ }^{8,9}$ Here we set out to explore what effect flow had on NP uptake by monocytes/ macrophages, and describe the physical rationale for these phenomena. Furthermore, we pursued a cell-based system to transport NP across an endothelial barrier in a hydrodynamic, multicellular in vitro model. We tested whether monocytes/ macrophages may serve as viable carriers to transport NP across biological barriers, i.e., as a cellular "Trojan horse."

There are several cellular candidates in the circulation which may act as NP Trojan horses such as red blood cells, monocytes/macrophages, $\mathrm{T}$ cells, B cells, or dendritic cells because of their proximity to circulation. ${ }^{13}$ In this study, we 
focused on monocytes/macrophages as a model cell type because they phagocytose nanomaterials and are mobile within tissue. ${ }^{15}$ Macrophages serve several physiological functions such as wound healing, host defense, and immune regulation. Monocytes, which originate from the hematopoietic stem cell line, circulate in the bloodstream and can be signaled to cross endothelial barriers via luminal surface markers such as intercellular adhesion molecule (ICAM)-1 and vascular cell adhesion molecule (VCAM)-1. ${ }^{16,17}$ Following diapedesis, monocytes differentiate into phagocytic macrophages (or dendritic cells) and can migrate through tissue interstitium to sites of inflammation. Furthermore, it has been shown that macrophages have been associated with solid tumors and may either positively or negatively affect therapeutic outcomes. ${ }^{18}$ Thus, it may be of interest to utilize monocytes/macrophages to either target tumors or as therapeutic targets themselves. In any case, it is necessary to understand both how these leukocytes and NP interact at the endothelial barrier.

In this study, we used fluorescent silica nanoparticles (F$\mathrm{SiO}_{2} \mathrm{NP}$ ) of approximately $60 \mathrm{~nm}$ diameter as a model particle system to study the NP uptake and transport by J774A.1 cells, a mouse monocyte/macrophage cell line, under hydrodynamic shear stress $\left(\tau_{\mathrm{w}}\right)$. NP were synthesized using a modified Stöber approach, ${ }^{19,20}$ and characterized via transmission electron microscopy (TEM), dynamic light scattering (DLS) and zeta $(\zeta)$-potential measurements. In vitro live cell imaging revealed cellular uptake of NP by J774A.1 cells over time. We used a custom-made flow chamber setup for a side-by-side comparison of static conditions to $\tau_{\mathrm{w}}$ up to $1.5 \mathrm{dyn} / \mathrm{cm}^{2}$. Importantly, NP uptake by J774A.1 cells adherent to recombinant ICAM-1 was significantly stronger under physiological flow than under static conditions. In order to understand this phenomenon, we developed a mathematical explanation that described the effect of flow on $\mathrm{F}-\mathrm{SiO}_{2} \mathrm{NP}$ on particle-cell contact. By modifying the system, we could study $\mathrm{F}-\mathrm{SiO}_{2} \mathrm{NP}$ uptake and transport by J774A.1 while adherent to green fluorescent protein (GFP)positive primary mouse lung endothelial cells ( $\mathrm{pMLuEC}$ ). Indeed, J774A.1 cells arrested on the pMLuEC and started uptake immediately upon NP supply under flow. Subsequently, NP-loaded J774A.1 cells diapedesed across the pMLuEC layer with the NPs concentrated in their uropod. These data demonstrate increased NP uptake by J774A.1 under flow and provide a physical rationale for how in vitro flow mediates this phenomenon. Moreover, the dynamic coculture system provided evidence that monocytes/macrophages may act as transporters to move NP across from the circulation across biological barriers such as the endothelium.

\section{EXPERIMENTAL SECTION}

Reagents. All solvents used were analytical reagent grade unless specified otherwise. Rhodamine B isothiocyanate (RhoB, mixed isomers), tetraethyl orthosilicate (TEOS, 98\%), (3-aminopropyl) triethoxysilane (APTES, 98\%), 28-30\% $\mathrm{NH}_{3}$ basis ammonium hydroxide solution $\left(\mathrm{NH}_{4} \mathrm{OH}\right)$, and absolute ethanol (EtOH, 99.8\%) were supplied by Sigma-Aldrich.

F-SiO ${ }_{2}$ NP Synthesis. NP were synthesized as previously described in the literature. ${ }^{19,20}$ Initially, RhoB was conjugated to the available amine group of APTES by dissolving $10 \mathrm{mg}(18 \mu \mathrm{mol})$ RhoB into 1 $\mathrm{mL}$ EtOH. Next, $15 \mu \mathrm{L}(64 \mu \mathrm{mol})$ APTES was added and the solution was stirred overnight protected from light. RhoB-conjugated APTES (RhoB-APTES) was used without further purification.

$\mathrm{F}-\mathrm{SiO}_{2} \mathrm{NP}$ were synthesized following a modified Stöber approach. $13.5 \mathrm{~mL}$ of Milli- $\mathrm{Q} \mathrm{H}_{2} \mathrm{O}$ (resistivity $=18.2 \mathrm{M} \Omega-\mathrm{cm}$ ), $208 \mathrm{~mL} \mathrm{EtOH}$, and $7.8 \mathrm{~mL} \mathrm{NH} \mathrm{NH}_{4} \mathrm{OH}$ were added to a round-bottomed flask. The solution was then brought to $60{ }^{\circ} \mathrm{C}$ with stirring. Twenty-two $\mathrm{mL}$ $(98.5 \mathrm{mmol})$ TEOS were added to the solution and stirred for $3 \mathrm{~min}$. Next, $600 \mu \mathrm{L}$ of RhoB-APTES were added directly to the solution and the reaction was continued for $3 \mathrm{~h}$. The solution was then allowed to cool to room temperature, and the $\mathrm{F}-\mathrm{SiO}_{2} \mathrm{NP}$ product was dialyzed (regenerated cellulose, $12-14 \mathrm{kDa}$ molecular weight cut off) for 1 week in Milli- $\mathrm{Q}_{2} \mathrm{O}$. Initial dialysis exchanges were done in EtOH to remove excess free RhoB. Particles were filtered through a $0.2 \mu \mathrm{m}$ poly(ether sulfone) membrane filter and stored at $4{ }^{\circ} \mathrm{C}$.

Nanoparticle Characterization. NP size, size distribution, and charge were characterized via transmission electron microscopy (TEM), dynamic light scattering (DLS), and zeta potential ( $\zeta$ potential) measurements. TEM images were acquired on a Tecnai G2 Spirit TEM (FEI; Frankfurt, Germany) operating at $120 \mathrm{kV}$ with a Veleta CCD camera (Olympus; Volketswil, Switzerland). NP core diameters $\left(\mathrm{d}_{\mathrm{c}}\right)$ were estimated using size distribution analysis software in FIJI (ImageJ 1.51g, National Institutes of Health; Bethesda, MD, USA). ${ }^{21}$ DLS was acquired using a 3D LS spectrometer (LS Instruments; Fribourg, Switzerland). The primary laser beam was formed by a linearly polarized and collimated Cobolt $05-01$ diode pumped solid state laser $(\lambda=660 \mathrm{~nm}, \mathrm{P} \max =500 \mathrm{~mW})$. DLS measurements were made at $25^{\circ} \mathrm{C}$ and scattering angles of 60,90 , and $120^{\circ}$. $\zeta$-potential measurements were performed on a phase amplitude light scattering (PALS) 90Plus zetasizer (Brookhaven Instruments; Hotsville, NY, USA). NP were dispersed into a phosphate buffered saline (PBS) diluted 1:10 in Milli-Q H2O, and the mean $\zeta$-potential was computed using the Smoluchowski equation. ${ }^{22}$

Cell Systems. J774A.1 mouse monocytes/macrophages (J774A.1) were supplied by American Type Culture Collections (LGC Standards; Wesel, Germany). Cells were cultured in Roswell Park Memorial Institute 1640 medium (RPMI-1640, Gibco) supplemented with 10 vol \% fetal bovine serum (FBS) and 1 vol \% penicillinstreptomycin (pen-strep) in a humidified incubator at $37^{\circ} \mathrm{C}$ and $5 \%$ $\mathrm{CO}_{2}$. Flow experiments were conducted in migration assay medium (MAM, phenol red-free Dulbecco's Modified Eagle Medium (DMEM, Gibco) supplemented with 5 vol \% calf serum, $25 \mathrm{mM}$ HEPES, and 4 $\mathrm{mM}$ L-glutamine). Prior to the flow experiments, J774A.1 cells were pretreated with interferon (IFN) $-\gamma$ at $103 \mathrm{U} / \mathrm{ml}$ for $16-24 \mathrm{~h}$ in order to induce an activated state in which the integrin ligand of ICAM-1, named lymphocyte function-associated antigen-1 (LFA-1), is upregulated and activated. ${ }^{23}$

pMLuEC were isolated from LifeAct-GFP transgenic C57BL/6 mice $^{24}$ and cultured as published. ${ }^{25}$ LifeAct-GFP signal was present in all endothelial cells and thus ultimately differentiated pMLuEC from the unstained J774A.1 cells. For the NP uptake and transport experiments, pMLuEC between passage 6 to 9 was grown to confluency on laminin precoated optical-bottom culture dishes for 3 days. Sixteen to twenty hours before the experiments, pMLuEC was stimulated with $10 \mathrm{ng} / \mathrm{mL}$ tumor necrosis factor (TNF)- $\alpha$ to increase ICAM-1 cell surface levels.

Wall Shear Stress and Shear Rate Calculations. Wall shear stress, $\tau_{\mathrm{w}}$, was calculated using the equation

$$
\tau_{\mathrm{w}}=\frac{3}{2} \frac{\mu \mathrm{Q}}{w\left(\frac{h}{2}\right)^{2}}
$$

Here, $\mu$ is the viscosity of MAM at $37^{\circ} \mathrm{C}\left(0.0083 \mathrm{dyn} \cdot \mathrm{s} / \mathrm{cm}^{2}\right), Q$ is the volumetric flow rate in $\mathrm{cm}^{3} / \mathrm{s}, w$ is the chamber width $(0.2 \mathrm{~cm})$, and $h$ is the chamber height $(0.034 \mathrm{~cm})$. Calculating the shear stress rate, $\dot{\gamma}$, was done with the equation

$$
\dot{\gamma}=\frac{\tau_{\mathrm{w}}}{\mu}
$$

Coating with Recombinant ICAM-1 and Nanoparticle Flow Experiments. Coating of optical-bottom culture dishes with recombinant mouse intercellular adhesion molecule 1 (recombinant ICAM-1, R\&D Systems) at $100 \mathrm{nM}$ was performed exactly as described before. $^{26}$

In vitro live-cell time lapse imaging of nanoparticle uptake under hydrodynamic conditions were performed in a custom-made micro- 
fluidic system. ${ }^{27,28} \mathrm{~A}$ silicone mask along with the upper flow chamber assembly was mounted via magnets on an optical-bottom culture dish (ibidi GmbH; Planegg, Germany) coated with recombinant ICAM-1 or covered with a monolayer of pMLuEC. Flow inlet and outlet allow for unidirectional flow via a Harvard Apparatus syringe pump. J774A.1 cells were introduced to the flow system at a low $\tau_{\mathrm{w}}\left(0.1 \mathrm{dyn} / \mathrm{cm}^{2}\right)$ and allowed to arrest over a period of $4 \mathrm{~min}$. Flow was then increased to physiological $\tau_{\mathrm{w}}\left(1.5 \mathrm{dyn} / \mathrm{cm}^{2}\right)$ for $1 \mathrm{~min}$ and $\mathrm{F}-\mathrm{SiO}_{2} \mathrm{NP}$ were supplied at $20 \mu \mathrm{g} \mathrm{NP} / \mathrm{mL}$ (approximately $8 \times 10^{10} \mathrm{NP} / \mathrm{mL}$ ), after which flow was either stopped, reduced or kept constant to expose J774A.1 cells to NP at three different $\tau_{\mathrm{w}}: 0.0,0.1$, and $1.5 \mathrm{dyn} / \mathrm{cm}^{2}$. Time lapse imaging at $10 \times$ objective magnification was acquired on an AxioObserver.Z1 inverted fluorescent microscope (Carl Zeiss AG; Feldbach, Switzerland) at $37{ }^{\circ} \mathrm{C}$ at 12 frames per minute. The $\tau_{\mathrm{w}}$ values of $0.0,0.1$, and $1.5 \mathrm{dyn} / \mathrm{cm}^{2}$ corresponded with shear stress rates $(\dot{\gamma})$ of $0,1.2$, and $180 \mathrm{~s}^{-1}$, respectively. The upper $\tau_{\mathrm{w}}$ was chosen as it is physiologically similar to that found in postcapillary vessels, ${ }^{27,29,30}$ the low $\tau_{\mathrm{w}}$ mimics physiological conditions such as fluid perfusion through tissues, ${ }^{31,32}$ and the $0.0 \mathrm{dyn} / \mathrm{cm}^{2}$ mimics current static in vitro experimental designs.

Automated Analysis of F-SiO 2 NP Uptake. Video analysis was performed to compare the uptake of NP under the different flow conditions. The differential interference contrast (DIC), i.e. white light, and fluorescent $\mathrm{Cy} 3$, i.e., rhodamine NP, channels from the previously obtained movie files were separated and the frames outside the range of interest were cropped. Both separated movie files were then imported into $\mathrm{FIJI},{ }^{21}$ and each channel was exported as individual frames. To analyze the uptake of NP, we wrote a MATLAB script (MATLAB R2015b, The MathWorks Inc., Natick, MA, 2000). From the DIC image, a binary matrix outlining the cell border was created. The outline was then filled, resulting in an image where the area covered by a cell was positive (white or 1) while the uncovered area remained negative (black or 0 ). All cells that contacted the image border were removed from the image and a size range threshold was determined in order to eliminate cell clusters and small artifacts. The Cy3 channel frames were then multiplied pixel by pixel with the corresponding DIC images, resulting in an elimination of rhodamine signal that does not overlay with a cell, as it was multiplied by 0 . The simple addition of all the remaining intensity and subsequent division by the area covered with cells in $\mu \mathrm{m}^{2}$ yielded mean fluorescent intensity per cell area for every frame.

\section{RESULTS AND DISCUSSION}

Nanoparticle Synthesis and Characterization. F$\mathrm{SiO}_{2} \mathrm{NP}$ were used as a model NP system. This particle system was chosen due to its well-established synthesis and the clinical relevance of $\mathrm{F}-\mathrm{SiO}_{2} \mathrm{NP}$ as biomedical imaging agents. ${ }^{33} \mathrm{~F}$ $\mathrm{SiO}_{2} \mathrm{NP}$ of approximately $60 \mathrm{~nm}$ diameter and doped with the fluorophore rhodamine $\mathrm{B}$ were synthesized using a modified Stöber method. $\mathrm{F}-\mathrm{SiO}_{2} \mathrm{NP}$ core and hydrodynamic diameters were confirmed to be 59 (TEM) and $64 \mathrm{~nm}$ (DLS), respectively (Table 1 , Figure 1). $\zeta$-potential was $-36 \mathrm{mV}$ (Table 1). Silica NP $\left(\mathrm{SiO}_{2} \mathrm{NP}\right)$ are often used as model particles because they are relatively inert from a biological standpoint $^{34}$ and are frequently used as cellular probes or imaging agents preclinically. ${ }^{35,36}$ Moreover, small $10 \mathrm{~nm}$ F$\mathrm{SiO}_{2} \mathrm{NP}$ are in clinical trials as targeted, intraoperative imaging

\section{Table 1. Nanoparticle Characterization}

$\begin{array}{ll}\text { diameter, TEM }\left(d_{\mathrm{c}}\right)(\mathrm{nm}) & 59 \pm 6 \\ \text { diameter, DLS }\left(d_{\mathrm{H}}\right)(\mathrm{nm}) & 63 \pm 22^{a} \\ & 64 \pm 24^{b} \\ \text { zeta potential }(\zeta)(\mathrm{mV}) & -36 \pm 1^{b}\end{array}$

${ }^{a}$ Measurements performed in Milli- $\mathrm{QH}_{2} \mathrm{O}{ }^{b}$ Measurements performed in $0.1 \times$ phosphate buffered saline.

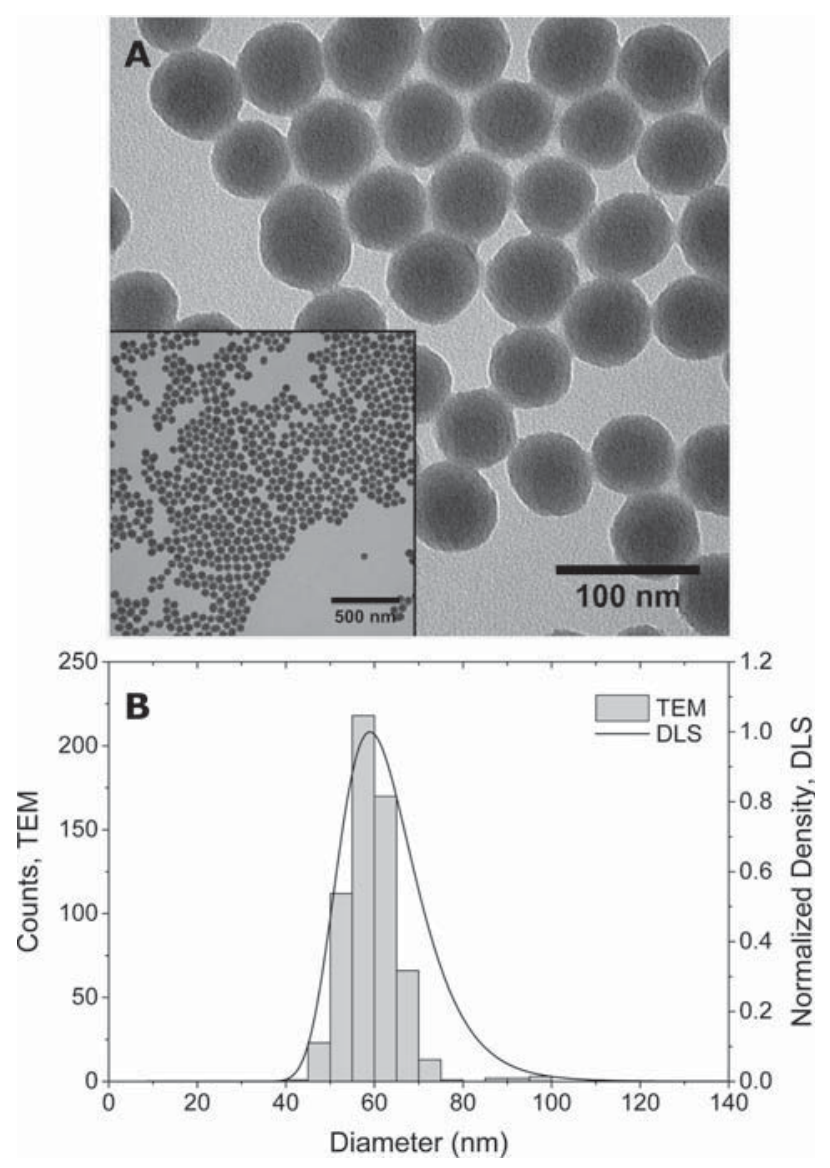

Figure 1. Characterization of $\mathrm{F}_{-} \mathrm{SiO}_{2} \mathrm{NP}$. (A) Transmission electron microscopy (TEM) image showing NP shape and size. Scale bar represents $100 \mathrm{~nm}$. (A, inset) Lower-magnification TEM image of $\mathrm{F}$ $\mathrm{SiO}_{2}$ NP. Scale bar represents $500 \mathrm{~nm}$. (B) Size distribution was determined by TEM and presented as a histogram and dynamic light scattering (DLS) showing hydrodynamic diameter size distribution.

agents for cancer resection (NCT02106598, www.clinicaltrials. gov. Our choice in NP size was in part because particle around $50 \mathrm{~nm}$ have been shown to be readily internalized by cells in comparison with particles $<20 \mathrm{~nm}$ or $>200 \mathrm{~nm}^{37,38}$ By covalently conjugating the fluorophore to a silica precursor, we ensure that the rhodamine $\mathrm{B}$ dye remains encapsulated within the silica NP matrix and does not leach out of the nanomaterial. Thus, the $\mathrm{F}-\mathrm{SiO}_{2} \mathrm{NP}$ present a robust platform for examining NP interactions under flow.

Physiological Flow Increases Nanoparticle Uptake by Monocytes/Macrophages. To analyze the uptake of NP by monocytes/macrophages from the circulation in an in vitro model, we took advantage of a custom-made flow chamber (Figure 2) that allows imaging of the dynamic spatiotemporal behavior of leukocytes using light microscopy while physiological flow is applied. ${ }^{27}$ In previous studies, this in vitro tool has proven valuable in resolving the differential roles of various endothelial cell adhesion molecules for the extravasation of $\mathrm{T}$ cells and neutrophils. ${ }^{26,39,40}$ In vitro live cell imaging revealed arrest of J774A.1 cells on recombinant ICAM-1 under low flow and their sustained shear resistant adhesion under physiological flow (Figure 3). NP were delivered together with the onset of physiological flow (Figure 3C). To examine the effect of various $\tau_{\mathrm{w}}$ on the NP uptake, we exposed adherent J774A.1 to physiological flow $\left(1.5 \mathrm{dyn} / \mathrm{cm}^{2}\right)$, low flow $\left(0.1 \mathrm{dyn} / \mathrm{cm}^{2}\right)$, or no flow over a period of $10 \mathrm{~min}$ (Figure 3C). Uptake of F- 


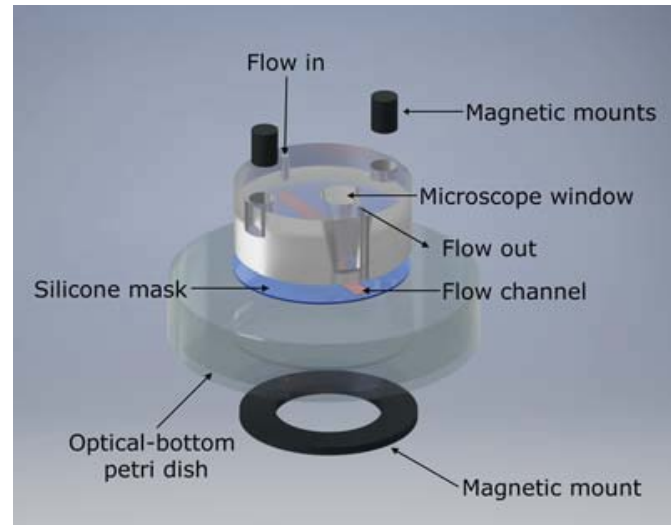

Figure 2. Expanded schematic illustration of the custom-built flow chamber. The flow chamber is mounted onto an optical-bottom Petri dish and secured into place by magnets. A silicone mask forms the flow channel by spacing a gap $(10 \mathrm{~mm} \times 2 \mathrm{~mm} \times 0.34 \mathrm{~mm})$ between the Petri dish and the chamber mount.

$\mathrm{SiO}_{2} \mathrm{NP}$ by J774A.1 cells occurred at all conditions documented through an increase of red fluorescence that accumulated within the J774A.1 over time (Figure 3). However, a side-by-side comparison of the NP fluorescence increase in J774A.1 cells exposed to $1.5 \mathrm{dyn} / \mathrm{cm}^{2}$ to conditions in which flow was absent or low revealed stronger NP accumulation under physiological flow. Significantly different uptake between $1.5 \mathrm{dyn} / \mathrm{cm}^{2}$ and 0.0 or $0.1 \mathrm{dyn} / \mathrm{cm}^{2}$ occurred already at 1 and $2 \mathrm{~min}$, respectively, after J774A.1 cells were exposed to the NP (Figure 4, Videos S1-S3).

To verify that $\mathrm{F}-\mathrm{SiO}_{2} \mathrm{NP}$ were in fact taken up by J774A.1 cells, rather than simply adsorbing to the cell surface, we fixed J774A.1 cells while they were adhered to recombinant ICAM-1 under flow and stained for filamentous actin (F-actin) and cell nuclei to demark the intracellular from membranous compartment. Maximum intensity projection of 3D laser scanning confocal microscopic images proved intracellular localization of the red fluorescent $\mathrm{F}-\mathrm{SiO}_{2} \mathrm{NP}$ (Figure S1). Taken together, we here demonstrated that monocytes/macrophages adherent to recombinant ICAM-1 and exposed to physiological flow show an increased activity in the uptake of NP compared to monocytes/macrophages under static conditions.

A review of the literature may be able to provide explanation as to why an increase in hydrodynamic shear stress leads to an increase in NP uptake, as the effect of flow on NP behavior and cellular interactions has been previously investigated. ${ }^{7,41-47}$ NP-cell interactions (e.g., cellular uptake, cytotoxicity) are governed by physicochemical properties such as size, shape, and surface charge as well as dependent on the system employed (e.g., cell type, flow conditions). To be certain, there are numerous biological factors which must also be considered when investigating NP cellular uptake. Changes in cell type or
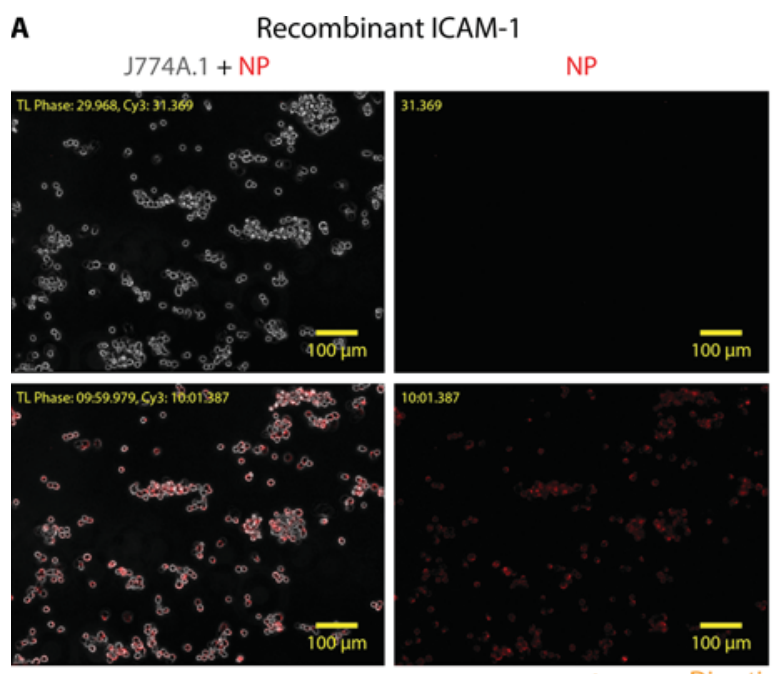

B $J 774 \mathrm{~A} .1+\mathrm{NP}+\mathrm{pMLuEC}$ pMLuEC
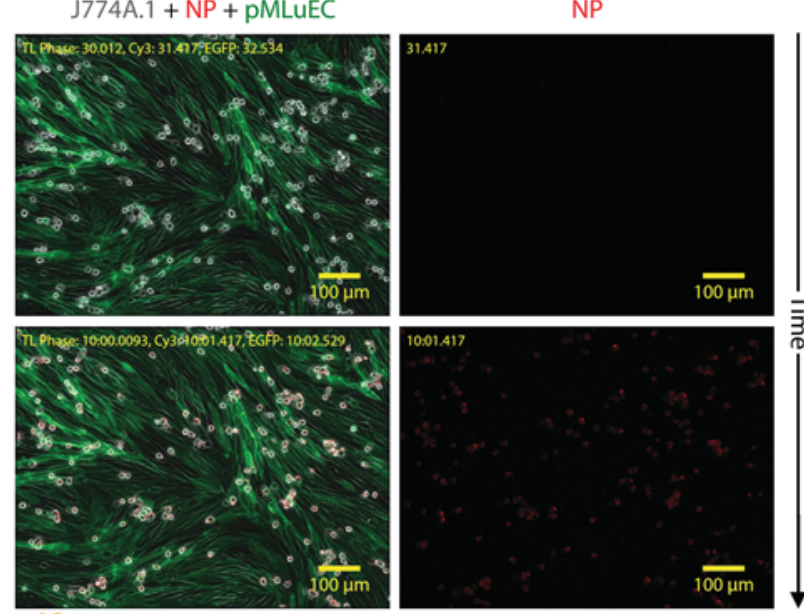

\section{C}

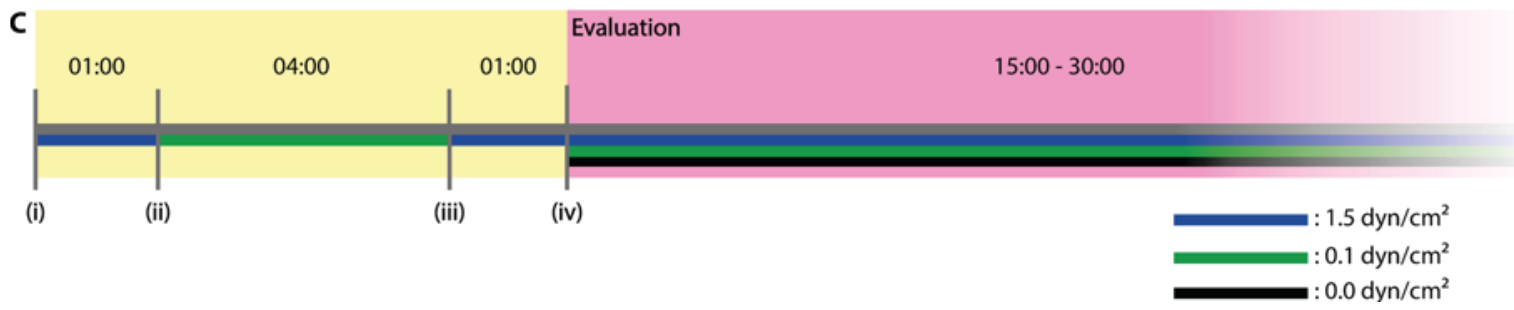

Evaluation

of flow

Figure 3. Images captured of the shear resistant arrest and NP uptake of J774A.1 arrested on (A) a recombinant ICAM-1 surface or (B) TNF- $\alpha$ activated pMLuEC. Upper panels indicate early time points at $30 \mathrm{~s}$ following the onset of physiological shear $\left(1.5 \mathrm{dyn} / \mathrm{cm}^{2}\right)$ to remove nonadherent J774A.1. Lower panels are at $10 \mathrm{~min}$ after the onset of physiological shear (and $9 \mathrm{~min}$ after the introduction of $\mathrm{F}-\mathrm{SiO}_{2} \mathrm{NP}$ ). Scale bars represent 100 $\mu \mathrm{m}$ and time is given for the transmitted light phase contrast (TL Phase), Cy3 fluorescent NPs (Cy3) or green fluorescent protein (GFP, pMLuEC) channels in units [min:sec.ms]. The orange arrow represents the direction of flow in all image panels. (C) Schematic representation of the flow experiments with time increments (in minutes) for each phase of the experiment: (i) The aspiration phase where J774A.1 mouse monocytes/ macrophages are introduced to the system at $1.5 \mathrm{dyn} / \mathrm{cm}^{2}$, (ii) the accumulation phase where J774A.1 attach to the surface at $0.1 \mathrm{dyn} / \mathrm{cm}^{2}$, (iii) removal of nonadherent J774A.1 byonset of physiological shear to $1.5 \mathrm{dyn} / \mathrm{cm}^{2}$, (iv) introduction of $\mathrm{F}-\mathrm{SiO}_{2} \mathrm{NP}_{\text {to }}$ the system. In the still images $(\mathrm{A}$ and $\mathrm{B}), t=0$ is set at (iii). 


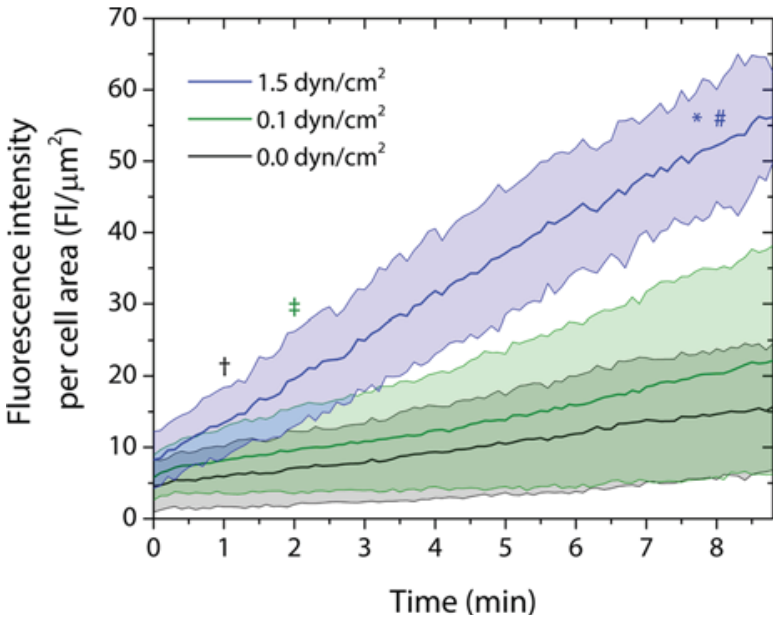

Figure 4. Uptake of $\mathrm{F}-\mathrm{SiO}_{2} \mathrm{NP}$ by J774A.1 increases with physiological flow. The uptake of $\mathrm{F}-\mathrm{SiO}_{2} \mathrm{NP}$ is measured by the fluorescent intensity per cell area in the absence of flow (black line, $0.0 \mathrm{dyn} / \mathrm{cm}^{2}$ ), at low flow (green line, $0.1 \mathrm{dyn} / \mathrm{cm}^{2}$ ) and at physiological flow (blue line, 1.5 $\left.\mathrm{dyn} / \mathrm{cm}^{2}\right)$ over a period of $9 \mathrm{~min}$. Solid lines represent mean values \pm standard deviation $(n \geq 3)$. ${ }^{\dagger, \hbar}$ Represent the time at which there was a statistically significant difference in fluorescent intensity per cell area between physiological flow and the absence of flow $\left({ }^{\dagger}\right)$, and physiological flow and low flow $\left({ }^{\ddagger}\right)$ as determined by a Student's $t$ test $(p<0.05)$. *Indicates a statistically significant difference between linear regression model slope values for each data set compared via a one-way ANOVA with Tukey's honestly significant difference (HSD) comparison of means $(p<0.05)$. " Indicates a statistically significant difference between fluorescent intensity values normalized by cell area at the final time point compared to the other shear stress conditions as determined by a one-way ANOVA and Tukey's HSD test $(p<0.05)$.

serum source in supplemented media can influence the "biological identity" of the NPs, and further investigations are certainly necessary to elucidate how flow may affect these outcomes. $^{48-51}$ In fact, a recent study by Palchetti et al. ${ }^{52}$ showed that both time and flow influenced the formation of the protein corona on liposomal NPs, and this in turn could influence the uptake of NPs by cancer cells. However, we investigated the underlying physical principles that directly affect NP-cell interaction under hydrodynamic conditions. In a study on the uptake of differently charged liposomes and $\mathrm{SiO}_{2} \mathrm{NP}$ by myoblast cells, Hosta-Rigau and Städler ${ }^{45}$ showed that increasing the percentage of positively charged lipids in the approximately $150 \mathrm{~nm}$ diameter liposomes and increasing shear stress $\left(0.0,0.0146\right.$, and $\left.0.1460 \mathrm{dyn} / \mathrm{cm}^{2}\right)$ directly increased the association of liposomes with myoblasts. For poly(L-lysine) (PLL) or PLL/polymethacrylic acid (PMA)-coated $300 \mathrm{~nm}$ diameter $\mathrm{SiO}_{2} \mathrm{NP}$ the response also appeared to be related to particle surface charge. Positively charged PLL-coated $\mathrm{SiO}_{2} \mathrm{NP}$ showed an increase in myoblast association as $\tau_{\mathrm{w}}$ increased; however, for negatively charged PLL/PMA-coated $\mathrm{SiO}_{2} \mathrm{NP}$, an inverse relationship was observed. It is hard to discern here whether surface charge (no $\zeta$-potential measurements shown) or inherent material properties (e.g., PLL vs PMA) mediated the differences in NP association with myoblasts.

Gentile et al. $^{41}$ described the effect of differently shaped particles on their margination propensity, the accumulation of species (e.g., particles, leukocytes, etc.) at the outer walls of a vessel. It was shown that for $1 \mu \mathrm{m}$ diameter spherical $\mathrm{SiO}_{2}$ particles margination decreased with increasing shear rate $(\dot{\gamma})$. This would imply that NP margination does not explain our observed phenomena: the direct correlation between NP uptake and shear stress. However, particle margination may still explain the observed phenomenon. Namdee et al. ${ }^{53}$ showed that particles ( 0.2 to $2 \mu \mathrm{m}$ ) actively targeted to endothelial cells (ECs) via sialyl lewis ${ }^{A}\left(\mathrm{sLe}^{\mathrm{A}}\right)$, a ligand that is specific for $\mathrm{E}$ selectin which is expressed on inflamed ECs, exhibited higher levels of vascular targeting as $\dot{\gamma}$ increased from 100 to $500 \mathrm{~s}^{-1}$. Charoenphol et al. ${ }^{54}$ similarly showed that sLe $^{\mathrm{A}}$-targeted particles generally exhibited increased targeting of human umbilical vein endothelial cells (HUVEC) with increasing particle size and $\dot{\gamma}$. There was, however, no significant difference for particles $<2 \mu \mathrm{m}$ at higher $\dot{\gamma}$. The data for $500 \mathrm{~nm}$ particles though, while not statistically significant, suggests a similar trend. Comparison between these literature data can be complicated. Experiments are frequently done with different nanomaterials (e.g., with different material density, surface chemistry, colloidal stability, targeted vs nontargeted, or size/ shape), different in vitro experimental parameters (e.g., cell culture medium, media containing red blood cells, different cell types, flow systems), and analytical method/approach. For example, agent-based modeling studies of NP capillary transport in complete blood have emphasized the significant effect that red blood cells play on NP hemodynamics. ${ }^{47}$ In all such experimental designs, the flow studies were conducted with unidirectional, noncirculating flow. As such, it may be more prudent to look for a physical explanation to describe why increasing shear stress results in increased particle uptake, rather than attributing these phenomena to biological effects or NP properties.

Physical Explanation for Flow-Cell Uptake Phenomenon. We have developed a simplified mathematical model that attempts to provide a quantitative description of the effect of shear on the uptake rate of NP. The model starting point is the in vitro sedimentation, diffusion, and dosimetry (ISDD) model, developed by Hinderliter et al. ${ }^{55}$ The ISDD model used a diffusion-advection equation to describe the number of particles settling and diffusing toward cells lying at the bottom of a chamber. Quantitatively, the model main equation reads

$$
\frac{\partial c}{\partial t}=D \frac{\partial^{2} c}{\partial z^{2}}+V \frac{\partial c}{\partial z}
$$

In eq $3, c$ is the particle concentration, $z$ the vertical coordinate of the chamber, $D$ the particle diffusion coefficient, and $V$ the particle sedimentation velocity, the latter two given by

$$
\begin{aligned}
& D=\frac{k_{\mathrm{B}} T}{3 \pi \mu d_{\mathrm{H}}}, \\
& V=\frac{g \Delta \rho d_{\mathrm{P}}^{3}}{18 \mu d_{\mathrm{H}}}
\end{aligned}
$$

These variables are determined by temperature $(T)$, the Boltzmann constant $\left(k_{\mathrm{B}}\right)$, fluid viscosity $(\mu)$, particle hydrodynamic diameter $\left(d_{\mathrm{H}}\right)$, gravitational acceleration $(g)$, the difference in material and fluid density $(\Delta \rho)$, and particle core diameter $\left(d_{\mathrm{p}}\right)$. The diffusion-advection equation requires the following initial and boundary conditions

$$
c(z, t=0)=c_{0}
$$




$$
\left\{\begin{array}{c}
c(z=0, t)=0 \\
\left.D \frac{\partial c}{\partial z}\right|_{z=L}+V c(z=L, t)=0
\end{array}\right.
$$

The initial conditions states that the concentration of particles is initially uniform in the chamber and equal to the value $c_{0}$. The boundary conditions state that the concentration of particles drops to zero on the surface of the chamber where cells are located (i.e., the cells will uptake all the particles that they come in contact with), whereas the opposite surface is impermeable to particles.

In the case of flow in the channel directed along the main dimension of the channel, which we assume to have a parabolic profile, the transport equation becomes significantly more complicated as it becomes necessary to also account for transport in the horizontal direction (direction of motion of the fluid)

$$
\frac{\partial c}{\partial t}=D \frac{\partial^{2} c}{\partial z^{2}}+V \frac{\partial c}{\partial z}-4 V_{0} \frac{z}{h}\left(1-\frac{z}{h}\right) \frac{\partial c}{\partial x}+D \frac{\partial^{2} c}{\partial x^{2}}
$$

In the last equation (eq 7), $x$ is the horizontal coordinate along the channel, $h$ the height of the channel, and $V_{0}$ is the maximum flow velocity in the middle of the channel. It is further assumed that the flow profile is parabolic in the vertical direction. The equation is more complex than the conventional ISDD model, and requires some simplifications. First, diffusion in the horizontal direction will be neglected under the assumption that its effect is negligible compared to convection. Additionally, under flow the chamber is constantly receiving fresh particles, and is supposed to reach a steady state very rapidly. Therefore, we will assume that time dependence is negligible too. Thus, the final equation reads

$$
4 V_{0} \frac{z}{h}\left(1-\frac{z}{h}\right) \frac{\partial c}{\partial x}=D \frac{\partial^{2} c}{\partial z^{2}}+V \frac{\partial c}{\partial z}
$$

The corresponding boundary conditions for eq 8 are the following:

$$
\left\{\begin{array}{c}
c(x, z=0, t)=0 \\
D \frac{\partial c}{\partial z} I_{z=H}+V_{z} c(x, z=H, t)=0 \\
c(x=0, z, t)=c_{0}
\end{array}\right.
$$

These conditions state once more that the concentration of particles is zero in contact with the cells, that the opposite wall is impermeable to particles, and that the concentration profile of particles entering the chamber (via convection) is uniform and equal to $c_{0}$. The amount of particles taken up by the cells $(F)$ is calculated as follows

$$
F=S \int_{0}^{L}\left(\left.D \frac{\partial c}{\partial z}\right|_{z=0}+V_{z} c(x, z=0, t)\right) \mathrm{d} x
$$

where $S$ is the width of the chamber.

The solution of eq 8 provides concentration profiles along the chamber under steady-state conditions. It is possible to relate the computed profile along the chamber to the residence time of particles inside the chamber, which is calculated as the ratio between the volume of the chamber and the flow rate of the solution. The residence time is the time necessary for fresh solution to completely fill the chamber. Therefore, it is possible to calculate the number of residence times that the total duration of the experiment corresponds. For the two flow rates that have been experimentally probed $\left(0.1\right.$ and $\left.1.5 \mathrm{dyn} / \mathrm{cm}^{2}\right)$, the duration of the experiments $(10 \mathrm{~min})$ correspond to 42 and 614 times. This means that the chamber receives, respectively, an amount of solution equal to 42 or 614 times that necessary to fill it. It is finally possible to relate the amount of particles taken up by the cell as a function of time in all the cases, i.e., without flow and with flow. The results are shown in Figure 5A.
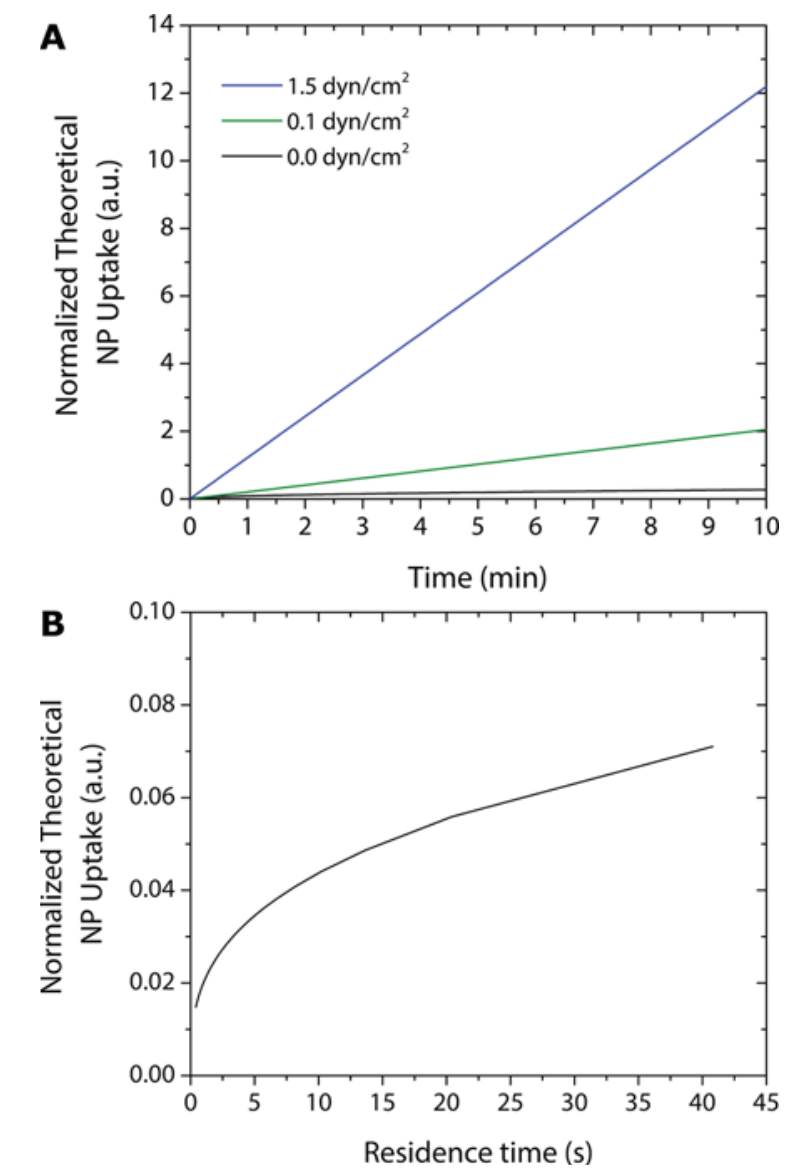

Figure 5. Physical modeling can explain the increase in NP uptake by cells under increasing shear stress. (A) Calculated quantity of particles taken up by the cells based on the different flow conditions. (B) Amount of particles taken up by the cells during one residence time, as a function of the residence time.

It can be observed that the amount to particles taken up by the cells increases linearly as a function of time, and is considerably higher for higher flow rates. The trend is similar to the extent of fluorescence measured experimentally, and shown in Figure 4. To understand the results of the simulations, we have calculated the amount of particles taken up by the cells in a period corresponding to the residence time, as a function of the residence time (which is inversely proportional to the flow rate). Figure 5B shows that as the flow rate increases (and the residence time decreases), the amount of particles in the cells decrease. This is due to the washing effect. Higher flow rates lead to steeper velocity gradients close the wall where cells are deposited, which drives the particles away from the surface. However, as the flow rate increases the cells are exposed, for a fixed time, to an overall much higher number of particles, which overcompensates for the decrease in particle number taken up by the cells during one residence time period. 


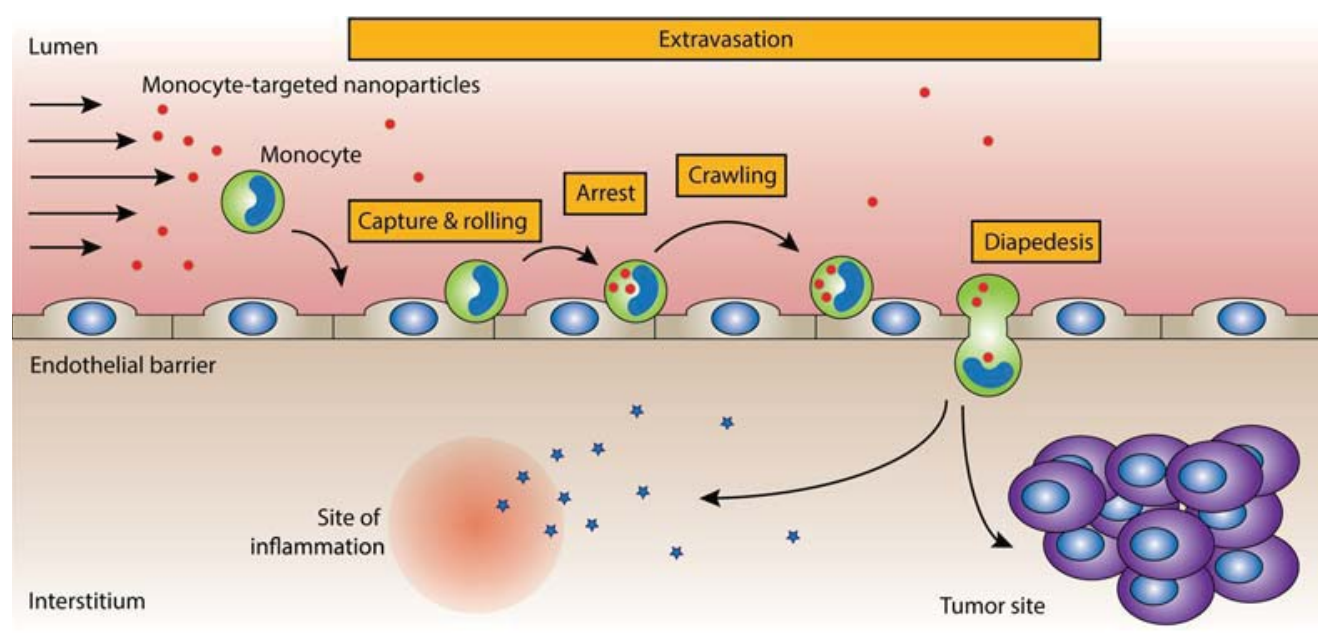

Figure 6. Schematic illustrating the concept of NP Trojan horse. Circulating cells (e.g., monocytes, red blood cells) can be preincubated with NP and introduced into systemic circulation, or targeted in situ by NP. These NP-carrying cells may then be attracted to physiological targets via naturally occurring processes, e.g., the recruitment of monocytes from circulation to sites of inflammation or tumors. Thus, NP-carrying cells may enable the particle payload to cross biological barriers, not wholly reliant on the physicochemical properties of the NP.

\section{J774A.1 Murine Monocytes/Macrophages Internalize} Nanoparticles while Dynamically Adherent to Endothelial Cells. Having determined that J774A.1 cells efficiently internalize NP while adherent to recombinant ICAM-1 and exposed to physiological flow, we next asked whether J774A.1 would likewise internalize NP when adherent to endothelial cells. We again took advantage of our custom-made flow chamber, which we mounted on a confluent monolayer formed by pMLuEC. This multicellular, hydrodynamic in vitro system was developed to mimic an activated endothelium in order to study the behavior of J774A.1 at this endothelial interface. To that point, $\mathrm{pMLuEC}$ were activated with TNF- $\alpha$ for $16 \mathrm{~h}$ prior to monocyte/macrophage exposure, and J774A.1 were similarly activated with IFN- $\gamma .{ }^{23}$ Treatment of pMLuEC with TNF- $\alpha$ induces an inflammatory phenotype with high levels of ICAM-1 and VCAM-1, thus mimicking an activated endothelial barrier (Figure S2).

In line with the previous experiments, a significant number of J774A.1 cells arrested on the surface of the pMLuEC and started a dynamic interaction behavior with the endothelial cells (Figure 3, Video S4). We then compared uptake of NP by J774A.1 cells while adherent to the endothelial cells under physiological flow $\left(1.5 \mathrm{dyn} / \mathrm{cm}^{2}\right)$ or under static conditions without flow $\left(0.0 \mathrm{dyn} / \mathrm{cm}^{2}\right)$ by time lapse imaging over $24 \mathrm{~min}$. Under both conditions, J774A.1 cells internalized NP over time (Figure 3B, Videos S5 and S6). NP internalization was a very robust event because all adherent J774A.1 cells accumulated red fluorescence over time without a single J774A.1 cell lacking NP uptake. Image series analysis showed stronger $\mathrm{F}_{-} \mathrm{SiO}_{2} \mathrm{NP}$ uptake by J774A.1 cells on the pMLuEC surface under physiological flow $\left(1.5 \mathrm{dyn} / \mathrm{cm}^{2}\right)$ compared to the static conditions (Figure S3). In striking contrast, the pMLuEC likewise exposed to NP did not accumulate any detectable fluorescence within the experimental period (Figure S4). Thus, internalization of NP by the endothelial cells under physiological flow or under static conditions remained undetectable, whereas J774A.1 cells readily internalized NP while adherent to the pMLuEC. These data indicate the potential for circulating monocytes to act as "Trojan" horses to carry NPs across the endothelium at sites of inflammation into the tissue.
Internalized NP are Transported Across an Endothelial Barrier. A major challenge of nanomedicine is to deliver optimal doses of NP therapeutic vectors or imaging agents to the correct physiological target. This entails navigating complex biological barriers (e.g., the blood-brain barrier or other continuous endothelium, extracellular matrix), traveling against pressure gradients (e.g., high interstitial fluid pressure), ${ }^{56,57}$ and avoiding premature clearance by the reticuloendothelial system. Some biomimetic strategies have attempted to camouflage particles with "cell-like" coatings to increase their utility. ${ }^{12,58-60}$ However, another proposed approach to overcome these challenges is to utilize natural cellular processes to localize NP at the site of interest. So-called cellular hitchhikers could potentially "hitch" a ride with circulating cells, which could then be attracted to target sites through chemokine signaling or natural cell recruitment processes (Figure 6). ${ }^{10,11,14}$ In such an approach, there are several viable candidates for cell-mediated NP delivery such as red blood cells, $\mathrm{T}$ cells, $\mathrm{B}$ cells, and monocytes/macrophages. ${ }^{13}$ In fact, Choi et al. ${ }^{11}$ have utilized systemically injected macrophages preloaded with fluorescent silica-coated gold NP to localize NP to brain tumor xenografts in mice, and others have similarly employed NP-toting macrophages to deliver particles to pathological targets. ${ }^{14,61}$

Monocytes/macrophages are particularly well-suited for such an application due to their physiological function. Macrophages are a cell type that propagate within a specific tissue or are derived from circulating monocytes which extravasate into tissue, either naturally or in response to some pathological condition (e.g., inflammation) and then mature into a variety of functional, tissue-specific macrophages. ${ }^{17,62}$ Mature macrophages naturally function to phagocytose foreign materials (e.g., particulate matter/NP, dead cells, cellular debris) and by exploiting, these traits it may be possible to shuttle NP across biological barriers via macrophage carriers.

We asked whether internalized NP would be transported by J774A.1 cells across the endothelial layer. To this end the behavior of J774A.1 cells on pMLuEC was carefully analyzed over a period of 24 min with and without the presence of flow $\left(1.5 \mathrm{dyn} / \mathrm{cm}^{2}\right)$. Under the flow condition, we observed J774A.1 cells continuously crawling (27\%), detaching from the endothelial surface (16\%), diapedesing across the endothelial 
layer $(8 \%)$, or merely remaining attached to the endothelium (50\%) (Figure 7 ). Comparatively, the static condition exhibited

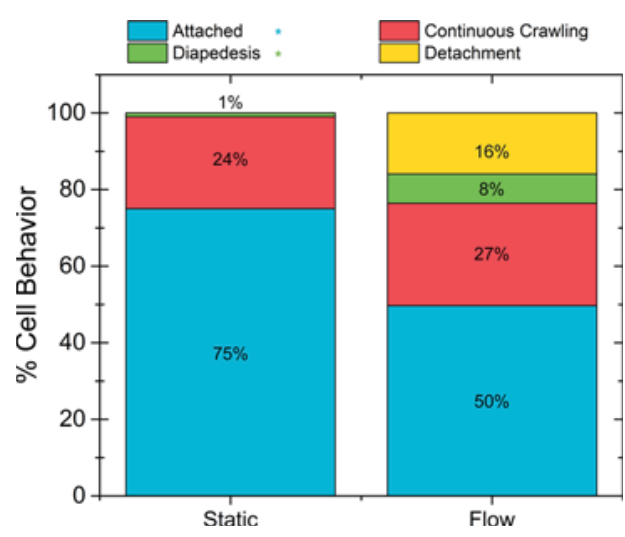

Figure 7. Macrophage behavior analysis under static and flow conditions $\left(1.5 \mathrm{dyn} / \mathrm{cm}^{2}\right)$ when attached to the pMLuEC layer. Their behavior was characterized in four ways: (1) attached macrophages attached to the endothelium but did not actively crawl; (2) continuous crawling macrophages attached to the endothelium, became polarized, and actively crawled on the endothelial cell surface; (3) diapedesis macrophages flattened and penetrated the endothelium; (4) detachment macrophages detached and drifted out of frame by the end of the imaging sequence ( $n \geq 100$ observations). *Signifies a statistically significant difference between the two conditions for the indicated behavior $(p<0.05)$.

different behavior with $24 \%$ continuously crawling, $0 \%$ detaching from the surface, only $1 \%$ diapedesing across the endothelium, and a majority $75 \%$ remaining attached to, however not crawling on, the endothelium. During diapedesis across the pMLuEC, NP accumulated very prominently in the uropod, the trailing plasma membrane protrusion in migrating leukocytes. ${ }^{63}$ Because diapedesis always starts at the front end of the polarized J774A.1 cells, NP transport across the endothelial layer was at the end of the diapedesis process (Figure 8, Video S7). It has previously been shown that shear stress is an important parameter for leukocyte diapedesis. ${ }^{64}$ Therefore, flow not only plays an important role in the uptake of particles by monocytes/macrophages but also influences their transendothelial migration. ${ }^{16,65}$

\section{CONCLUSIONS}

Here we have shown the $\tau_{\mathrm{w}}$-dependent uptake of $\mathrm{F}-\mathrm{SiO}_{2} \mathrm{NP}$ by J774A.1 cells that were attached to either a recombinant ICAM1 or pMLuEC surface. Physiological hydrodynamic shear mimicking blood flow strength at sites where extravasation does occur lead to an increase in particle uptake by monocytes/ macrophages adherent to ICAM-1 or endothelial cells over static or low flow conditions. Our data further provide a rational explanation for the increased NP uptake under hydrodynamic shear stress. Physical modeling suggests that this phenomenon is related to higher overall exposure to NP at higher flow rates. Importantly, the J774A.1 cells transported the phagocytosed NP across the endothelial layer. This indicates that monocytes/macrophages, through the process of extravasation, could act as carriers for particles across biological barriers and also supports a preliminary view of monocytes/ macrophages as transendothelial transporters for biomedical applications. The goal would be to utilize cellular carriers as socalled Trojan horses to deliver particles to pathological sites.

\section{ASSOCIATED CONTENT}

\section{S Supporting Information}

The Supporting Information is available free of charge on the ACS Publications website at DOI: 10.1021/acsami.7b03479.

Live-cell imaging video files showing particle uptake under static and flow conditions, description of video files, confocal microscopy figures, immunofluorescence images of activated endothelium, nanoparticle uptake analysis by J774A.1 monocyte/macrophage cells attached to pulmonary mouse lung endothelial cells, and fluorescent microscopy images (PDF)

Video $\mathrm{S} 1$, uptake of $\mathrm{F}-\mathrm{SiO}_{2} \mathrm{NP}$ under static conditions (AVI)

Video $\mathrm{S} 2$, uptake of $\mathrm{F}-\mathrm{SiO}_{2} \mathrm{NP}$ under low flow conditions (AVI)

Video $\mathrm{S} 3$, uptake of $\mathrm{F}-\mathrm{SiO}_{2} \mathrm{NP}$ under physiological flow conditions (AVI)
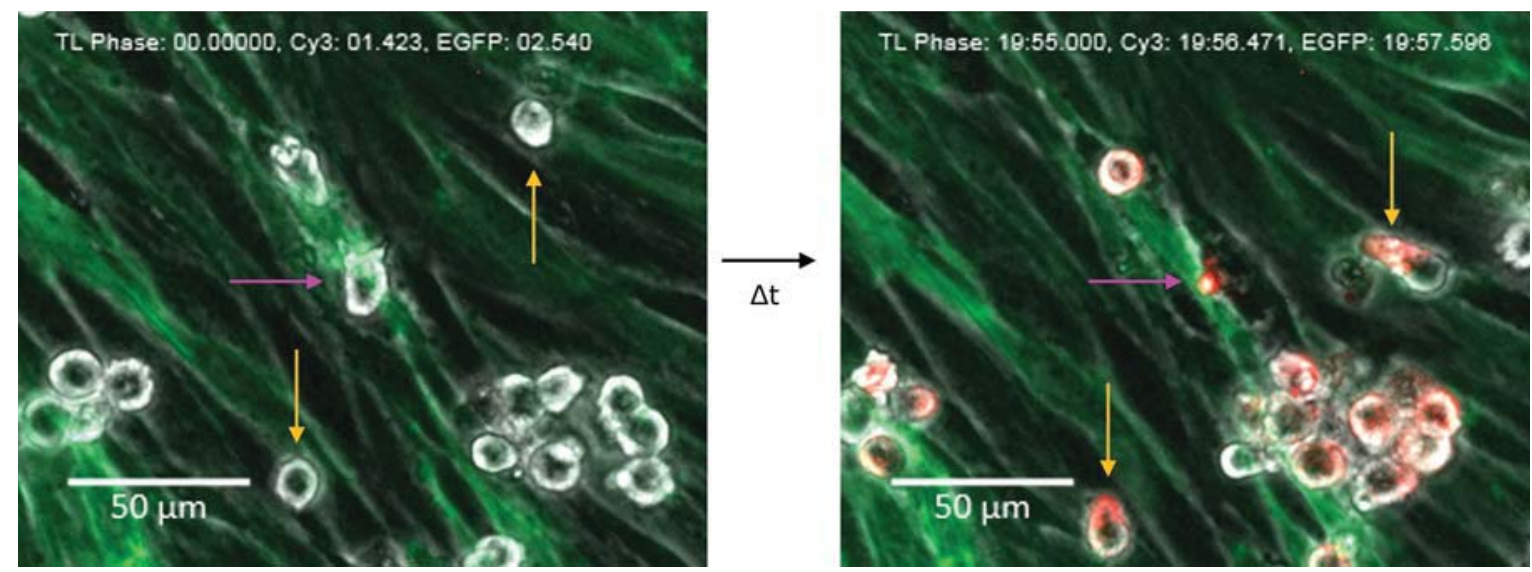

Figure 8. Initial (left) and final (right) frames captured from live-cell videos of NP uptake by J774A.1 mouse monocytes/macrophages (white) arrested onto TNF- $\alpha$ treated primary mouse lung endothelial cells (pMLEC) transfected with LifeAct GFP (green) for actin. J774A.1 cells attached to the pMLEC surface and phagocytosed NP (red) over a 20 min period. Polarized J774A.1 crawled along the pMLEC surface and NP were localized in the macrophage uropod (yellow arrows), and some J774A.1 extravasated through the pMLEC layer (magenta arrow). Scale bars represent $50 \mu \mathrm{m}$ and time is displayed in minutes [min:sec.ms]. Full videos found in the Supporting Information. 
Video S4, magnified image of J774A.1 cells interacting with the TNF-a stimulated pMLuECs (AVI)

Video S5, uptake of $\mathrm{F}-\mathrm{SiO}_{2} \mathrm{NP}$ by J774A.1 cells adherent to the pMLuEC layer under static conditions (AVI) Video S6, uptake of $\mathrm{F}_{-} \mathrm{SiO}_{2} \mathrm{NP}$ by J774A.1 attached to the pMLuEC layer under static conditions (AVI) Video S7, diapedesis of J774A.1 through the pMLuEC layer (AVI)

\section{AUTHOR INFORMATION}

\section{Corresponding Authors}

*E-mail: marco.lattuada@unifr.ch.

*E-mail: alke.fink@unifr.ch.

*E-mail: ruth.lyck@tki.unibe.ch.

\section{ORCID}

Thomas L. Moore: 0000-0002-7886-5245

Thomas Gruber: 0000-0001-5210-1995

Alke Petri-Fink: 0000-0003-3952-7849

\section{Notes}

The authors declare no competing financial interest.

\section{ACKNOWLEDGMENTS}

The authors thank Ana B. García Martín and Stefanie Hendriks for their excellent technical assistance, Dr. Sandor Balog for his helpful discussions and for providing the DLS analysis script, and Dr. Dedy Septiadi for his assistance with the MATLAB script. We are grateful for financial support from the Foundation for Clinical-Experimental Cancer Research and from the Swiss Multiple Sclerosis Society to R.L., the Swiss National Science Foundation through the National Centre of Competence in Research "Bio-Inspired Materials" to D.H., B.R.R, and A.P.F., and support from the Adolphe Merkle Foundation. Microscopy was performed on equipment supported by the Microscopy Imaging Center (MIC), Universität Bern, Switzerland.

\section{REFERENCES}

(1) Moore, T. L.; Graham, E.; Mattix, B.; Alexis, F. In Biomaterials Science: An Integrated Clinical and Engineering Approach; Rosen, Y., Elman, N., Eds.; CRC Press: Boca Raton, FL, 2010; Chapter 4, pp 85121.

(2) Heidel, J. D.; Davis, M. E. Clinical Developments in Nanotechnology for Cancer Therapy. Pharm. Res. 2011, 28, 187-199.

(3) Venditto, V. J.; Szoka, F. C. Cancer Nanomedicines: So Many Papers and So Few Drugs! Adv. Drug Delivery Rev. 2013, 65, 80-88. (4) Albanese, A.; Lam, A. K.; Sykes, E. a.; Rocheleau, J. V.; Chan, W. C. W. Tumour-on-a-chip Provides an Optical Window into Nanoparticle Tissue Transport. Nat. Commun. 2013, 4, 2718.

(5) Priwitaningrum, D. L.; Blondé, J. B. G.; van Baarlen, J.; Hennink, W. E.; Storm, G.; Le Gac, S.; Prakash, J. Tumor Stroma-containing 3D Spheroid Arrays: A Tool to Study Nanoparticle Penetration. J. Controlled Release 2016, 244, 257-268.

(6) Huh, D.; Matthews, B. D.; Mammoto, A.; Montoya-Zavala, M.; Hsin, H. Y.; Ingber, D. E. Reconstituting Organ-level Lung Functions on a Chip. Science 2010, 328, 1662-1668.

(7) Kim, Y.; Lobatto, M. E.; Kawahara, T.; Lee Chung, B.; Mieszawska, A. J.; Sanchez-Gaytan, B. L.; Fay, F.; Senders, M. L.; Calcagno, C.; Becraft, J.; Tun Saung, M.; Gordon, R. E.; Stroes, E. S. G.; Ma, M.; Farokhzad, O. C.; Fayad, Z. A.; Mulder, W. J. M.; Langer, R. Probing Nanoparticle Translocation across the Permeable Endothelium in Experimental Atherosclerosis. Proc. Natl. Acad. Sci. U. S. A. 2014, 111, 1078-1083.
(8) Valencia, P. M.; Farokhzad, O. C.; Karnik, R.; Langer, R. Microfluidic Technologies for Accelerating the Clinical Translation of Nanoparticles. Nat. Nanotechnol. 2012, 7, 623-629.

(9) Valencia, P. M.; Pridgen, E. M.; Rhee, M.; Langer, R.; Farokhzad, O. C.; Karnik, R. Microfluidic Platform for Combinatorial Synthesis and Optimization of Targeted Nanoparticles for Cancer Therapy. ACS Nano 2013, 7, 10671-10680.

(10) Choi, M.-R.; Stanton-Maxey, K. J.; Stanley, J. K.; Levin, C. S.; Bardhan, R.; Akin, D.; Badve, S.; Sturgis, J.; Robinson, J. P.; Bashir, R.; Halas, N. J.; Clare, S. E. A Cellular Trojan Horse for Delivery of Therapeutic Nanoparticles into Tumors. Nano Lett. 2007, 7, 37593765.

(11) Choi, M.-R.; Bardhan, R.; Stanton-Maxey, K. J.; Badve, S.; Nakshatri, H.; Stantz, K. M.; Cao, N.; Halas, N. J.; Clare, S. E. Delivery of Nanoparticles to Brain Metastases of Breast Cancer using a Cellular Trojan Horse. Cancer Nanotechnol. 2012, 3, 47-54.

(12) Parodi, A.; Quattrocchi, N.; van de Ven, A. L.; Chiappini, C.; Evangelopoulos, M.; Martinez, J. O.; Brown, B. S.; Khaled, S. Z.; Yazdi, I. K.; Enzo, M. V.; Isenhart, L.; Ferrari, M.; Tasciotti, E. Synthetic Nanoparticles Functionalized with Biomimetic Leukocyte Membranes Possess Cell-like Functions. Nat. Nanotechnol. 2013, 8, 61-68.

(13) Anselmo, A. C.; Mitragotri, S. Cell-mediated Delivery of Nanoparticles: Taking Advantage of Circulatory Cells to Target Nanoparticles. J. Controlled Release 2014, 190, 531-541.

(14) Anselmo, A. C.; Gilbert, J. B.; Kumar, S.; Gupta, V.; Cohen, R. E.; Rubner, M. F.; Mitragotri, S. Monocyte-mediated Delivery of Polymeric Backpacks to Inflamed Tissues: A Generalized Strategy to Deliver Drugs to Treat Inflammation. J. Controlled Release 2015, 199, 29-36.

(15) Digigow, R. G.; Vanhecke, D.; Rothen-Rutishauser, B.; Clift, M. J.; Petri-Fink, A. Uptake and Intracellular Fate of Peptide Surfacefunctionalized Silica Hybrid Magnetic Nanoparticles In Vitro. Part Part Syst. Charact 2015, 32, 188-196.

(16) Muller, W. A. Mechanism of Leukocyte Transendothelial Migration. Annu. Rev. Pathol.: Mech. Dis. 2011, 6, 323-344.

(17) Murray, P. J.; Wynn, T. A. Protective and Pathogenic Functions of Macrophage Subsets. Nat. Rev. Immunol. 2011, 11, 723-737.

(18) Ruffell, B.; Coussens, L. M. Macrophages and Therapeutic Resistance in Cancer. Cancer Cell 2015, 27, 462-472.

(19) Stöber, W.; Fink, A.; Bohn, E. Controlled Growth of Monodisperse Silica Spheres in the Micron Size Range. J. Colloid Interface Sci. 1968, 26, 62-69.

(20) Larson, D. R.; Ow, H.; Vishwasrao, H. D.; Heikal, A. A.; Wiesner, U.; Webb, W. W. Silica Nanoparticle Architecture Determines Radiative Properties of Encapsulated Fluorophores. Chem. Mater. 2008, 20, 2677-2684.

(21) Schindelin, J.; Arganda-Carreras, I.; Frise, E.; Kaynig, V.; Longair, M.; Pietzsch, T.; Preibisch, S.; Rueden, C.; Saalfeld, S.; Schmid, B.; Tinevez, J.-Y.; White, D. J.; Hartenstein, V.; Eliceiri, K.; Tomancak, P.; Cardona, A. Fiji: An Open-source Platform for Biological-image Analysis. Nat. Methods 2012, 9, 676-682.

(22) Smoluchowski, M. V. Zur Theorie der elektrischen Kataphorese und der Oberflächenleitung (Essai de théorie de la cataphorèse électrique et de la conduction superficielle). J. Phys. Theor. Appl. 1907, 6, 659-660.

(23) Pourshafie, M. R; Sonnenfeld, G. Treatment of an Infected Murine Macrophage Cell Line (J774A.1) with Interferon- $\gamma$ but Not Tumor Necrosis Factor- $\alpha$ or Live Mycobacterium intracellulare Alone Modulates the Expression of Adhesion Molecules. J. Interferon Cytokine Res. 1997, 17, 69-75.

(24) Riedl, J.; Flynn, K. C.; Raducanu, A.; Gartner, F.; Beck, G.; Bosl, M.; Bradke, F.; Massberg, S.; Aszodi, A.; Sixt, M.; Wedlich-Soldner, R. Lifeact mice for studying F-actin dynamics. Nat. Methods 2010, 7 , $168-169$.

(25) Dong, Q. G.; Bernasconi, S.; Lostaglio, S.; Wainstok De Calmanovici, R.; Martin-Padura, I.; Breviario, F.; Garlanda, C.; Ramponi, S.; Mantovani, A.; Vecchi, A. A General Strategy for Isolation of Endothelial Cells From Murine Tissues Characterization of Two Endothelial Cell Lines From the Murine Lung and 
Subcutaneous Sponge Implants. Arterioscler., Thromb., Vasc. Biol. 1997, $17,1599-1604$.

(26) Steiner, O.; Coisne, C.; Cecchelli, R.; Deutsch, U.; Engelhardt, B.; Lyck, R. Differential Roles for Endothelial ICAM-1, ICAM-2, and VCAM-1 in Shear-Resistant T Cell Arrest, Polarization, and Directed Crawling on Blood-Brain Barrier Endothelium. J. Immunol. 2010, 185, 4846-4855.

(27) Coisne, C.; Lyck, R.; Engelhardt, B. Live Cell Imaging Techniques to Study T Cell Trafficking across the Blood-Brain Barrier In Vitro and In Vivo. Fluids Barriers CNS 2013, 10, 7.

(28) Nitschké, M.; Aebischer, D.; Abadier, M.; Haener, S.; Lucic, M.; Vigl, B.; Luche, H.; Fehling, H. J.; Biehlmaier, O.; Lyck, R.; Halin, C. Differential Requirement for ROCK in Dendritic Cell Migration within Lymphatic Capillaries in Steady-state and Inflammation. Blood 2012, 120, 2249-2258.

(29) Giavazzi, R.; Foppolo, M.; Dossi, R.; Remuzzi, A. Rolling and Adhesion of Human Tumor Cells on Vascular Endothelium under Physiological Flow Conditions. J. Clin. Invest. 1993, 92, 3038-3044.

(30) Buchanan, C. F.; Verbridge, S. S.; Vlachos, P. P.; Rylander, M. N. Flow Shear Stress Regulates Endothelial Barrier Function and Expression of Angiogenic Factors in a 3D Microfluidic Tumor Vascular Model. Cell Adhesion \& Migration 2014, 8, 517-524.

(31) Tarbell, J. M.; Shi, Z.-D. Effect of the Glycocalyx Layer on Transmission of Interstitial Flow Shear Stress to Embedded Cells. Biomech. Model. Mechanobiol. 2013, 12, 111-121.

(32) Mitchell, M. J.; King, M. R. Computational and Experimental Models of Cancer Cell Response to Fluid Shear Stress. Front. Oncol. 2013, 3, 44.

(33) Phillips, E.; Penate-Medina, O.; Zanzonico, P. B.; Carvajal, R. D.; Mohan, P.; Ye, Y.; Humm, J.; Gönen, M.; Kalaigian, H.; Schöder, H.; Strauss, H. W.; Larson, S. M.; Wiesner, U.; Bradbury, M. S. Clinical Translation of an Ultrasmall Inorganic Optical-PET Imaging Nanoparticle Probe. Sci. Transl. Med. 2014, 6, 260ra149.

(34) Yu, T.; Malugin, A.; Ghandehari, H. Impact of Silica Nanoparticle Design on Cellular Toxicity and Hemolytic Activity. ACS Nano 2011, 5, 5717-5728.

(35) Wang, L.; Wang, K.; Santra, S.; Zhao, X.; Hilliard, L. R.; Smith, J. E.; Wu, Y.; Tan, W. Watching Silica Nanoparticles Glow in the Biological World. Anal. Chem. 2006, 78, 646-654.

(36) Korzeniowska, B.; Nooney, R.; Wencel, D.; McDonagh, C. Silica Nanoparticles for Cell Imaging and Intracellular Sensing. Nanotechnology 2013, 24, 442002.

(37) Chithrani, B. D.; Ghazani, A. A.; Chan, W. C. Determining the Size and Shape Dependence of Gold Nanoparticle Uptake in Mammalian Cells. Nano Lett. 2006, 6, 662-668.

(38) Fang, L.; Wu, S.-H.; Hung, Y.; Mou, C.-Y. Size Effect on Cell Uptake in Well-Suspended, Uniform Mesoporous Silica Nanoparticles. Small 2009, 5, 1408-1413.

(39) Lyck, R.; Lécuyer, M.-A.; Abadier, M.; Wyss, C. B.; Matti, C.; Rosito, M.; Enzmann, G.; Zeis, T.; Michel, L.; García Martín, A. B.; Sallusto, F.; Gosselet, F.; Deutsch, U.; Weiner, J. A.; SchaerenWiemers, N.; Prat, A.; Engelhardt, B. ALCAM (CD166) is Involved in Extravasation of Monocytes Rather than T Cells across the BloodBrain Barrier. J. Cereb. Blood Flow Metab. 2016, 0271678X1667863.

(40) Gorina, R.; Lyck, R.; Vestweber, D.; Engelhardt, B. B Integrinmediated Crawling on Endothelial ICAM-1 and ICAM-2 is a Prerequisite for Transcellular Neutrophil Diapedesis across the Inflamed Blood-Brain Barrier. J. Immunol. 2014, 192, 324-337.

(41) Gentile, F.; Chiappini, C.; Fine, D.; Bhavane, R. C.; Peluccio, M. S.; Cheng, M. M. C.; Liu, X.; Ferrari, M.; Decuzzi, P. The Effect of Shape on the Margination Dynamics of Non-neutrally Buoyant Particles in Two-dimensional Shear Flows. J. Biomech 2008, 41, 2312 2318.

(42) Gentile, F.; Curcio, A.; Indolfi, C.; Ferrari, M.; Decuzzi, P. The Margination Propensity of Spherical Particles for Vascular Targeting in the Microcirculation. J. Nanobiotechnol. 2008, 6, 9.

(43) Han, J.; Zern, B. J.; Shuvaev, V. V.; Davies, P. F.; Muro, S.; Muzykantov, V. Acute and Chronic Shear Stress Differently Regulate Endothelial Internalization of Nanocarriers Targeted to Platelet-
Endothelial Cell Adhesion Molecule-1. ACS Nano 2012, 6, 88248836.

(44) Samuel, S. P.; Jain, N.; O’Dowd, F.; Paul, T.; Kashanin, D.; Gerard, V. A.; Gun'ko, Y. K.; Prina-Mello, A.; Volkov, Y. Multifactorial Determinants that Govern Nanoparticle Uptake by Human Endothelial Cells under Flow. Int. J. Nanomed. 2012, 7, 2943-2956.

(45) Hosta-Rigau, L.; Städler, B. Shear Stress and its Effect on the Interaction of Myoblast Cells with Nanosized Drug Delivery Vehicles. Mol. Pharmaceutics 2013, 10, 2707-2712.

(46) Ucciferri, N.; Collnot, E. M.; Gaiser, B. K.; Tirella, A.; Stone, V.; Domenici, C.; Lehr, C. M.; Ahluwalia, A. In Vitro Toxicological Screening of Nanoparticles on Primary Human Endothelial Cells and the Role of Flow in Modulating Cell Response. Nanotoxicology 2014, 8, 697-708.

(47) Fullstone, G.; Wood, J.; Holcombe, M.; Battaglia, G. Modelling the Transport of Nanoparticles under Blood Flow using an Agentbased Approach. Sci. Rep. 2015, 5, 10649.

(48) Tenzer, S.; Docter, D.; Kuharev, J.; Musyanovych, A.; Fetz, V.; Hecht, R.; Schlenk, F.; Fischer, D.; Kiouptsi, K.; Reinhardt, C.; Landfester, K.; Schild, H.; Maskos, M.; Knauer, S. K.; Stauber, R. H. Rapid Formation of Plasma Protein Corona Critically Affects Nanoparticle Pathophysiology. Nat. Nanotechnol. 2013, 8, 772-781.

(49) Ritz, S.; Schöttler, S.; Kotman, N.; Baier, G.; Musyanovych, A.; Kuharev, J.; Landfester, K.; Schild, H.; Jahn, O.; Tenzer, S.; Mailänder, V. Protein Corona of Nanoparticles: Distinct Proteins Regulate the Cellular Uptake. Biomacromolecules 2015, 16, 1311-1321.

(50) Schöttler, S.; Klein, K.; Landfester, K.; Mailänder, V. Protein source and choice of anticoagulant decisively affect nanoparticle protein corona and cellular uptake. Nanoscale 2016, 8, 5526-5536.

(51) Lundqvist, M.; Augustsson, C.; Lilja, M.; Lundkvist, K.; Dahlbäck, B.; Linse, S.; Cedervall, T. The Nanoparticle Protein Corona Formed in Human Blood or Human Blood Fractions. PLoS One 2017, 12, e0175871.

(52) Palchetti, S.; Pozzi, D.; Capriotti, A. L.; Barbera, G. L.; Chiozzi, R. Z.; Digiacomo, L.; Peruzzi, G.; Caracciolo, G.; Laganà, A. Influence of Dynamic Flow Environment on Nanoparticle-Protein Corona: From Protein Patterns to Uptake in Cancer Cells. Colloids Surf., B 2017, 153, 263-271.

(53) Namdee, K.; Thompson, A. J.; Charoenphol, P.; Eniola-Adefeso, O. Margination Propensity of Vascular-targeted Spheres from Blood Flow in a Microfluidic Model of Human Microvessels. Langmuir 2013, 29, 2530-2535.

(54) Charoenphol, P.; Huang, R. B.; Eniola-Adefeso, O. Potential Role of Size and Hemodynamics in the Efficacy of Vascular-targeted Spherical Drug Carriers. Biomaterials 2010, 31, 1392-1402.

(55) Hinderliter, P. M.; Minard, K. R.; Orr, G.; Chrisler, W. B.; Thrall, B. D.; Pounds, J. G.; Teeguarden, J. G. ISDD: A Computational Model of Particle Sedimentation, Diffusion and Target Cell Dosimetry for In Vitro Toxicity Studies. Part. Fibre Toxicol. 2010, 7, 36.

(56) Heldin, C.-H.; Rubin, K.; Pietras, K.; Ostman, A. High Interstitial Fluid Pressure - An Obstacle in Cancer Therapy. Nat. Rev. Cancer 2004, 4, 806-813.

(57) Holback, H.; Yeo, Y. Intratumoral Drug Delivery with Nanoparticulate Carriers. Pharm. Res. 2011, 28, 1819-1830.

(58) Hu, C.-M.; Zhang, L.; Aryal, S.; Cheung, C.; Fang, R. H.; Zhang, L. Erythrocyte Membrane-camouflaged Polymeric Nanoparticles as a Biomimetic Delivery Platform. Proc. Natl. Acad. Sci. U. S. A. 2011, 108, 10980-10985.

(59) Mao, Z.; Cartier, R.; Hohl, A.; Farinacci, M.; Dorhoi, A.; Nguyen, T.-L.; Mulvaney, P.; Ralston, J.; Kaufmann, S. H. E.; Möhwald, H.; Wang, D. Cells as Factories for Humanized Encapsulation. Nano Lett. 2011, 11, 2152-2156.

(60) Peng, L.-H.; Zhang, Y.-H.; Han, L.-J.; Zhang, C.-Z.; Wu, J.-H.; Wang, X.-R.; Gao, J.-Q.; Mao, Z.-W. Cell Membrane Capsules for Encapsulation of Chemotherapeutic and Cancer Cell Targeting in Vivo. ACS Appl. Mater. Interfaces 2015, 7, 18628-18637.

(61) Doshi, N.; Swiston, A. J.; Gilbert, J. B.; Alcaraz, M. L.; Cohen, R. E.; Rubner, M. F.; Mitragotri, S. Cell-based Drug Delivery Devices 
Using Phagocytosis-resistant Backpacks. Adv. Mater. 2011, 23, H105H109.

(62) Mosser, D. M.; Edwards, J. P. Exploring the Full Spectrum of Macrophage Activation. Nat. Rev. Immunol. 2008, 8, 958-969.

(63) Sánchez-Madrid, F.; Serrador, J. M. Bringing Up the Rear: Defining the Roles of the Uropod. Nat. Rev. Mol. Cell Biol. 2009, 10, 353-359.

(64) Cinamon, G.; Shinder, V.; Alon, R. Shear Forces Promote Lymphocyte Migration Across Vascular Endothelium Bearing Apical Chemokines. Nat. Immunol. 2001, 2, 515-522.

(65) Schenkel, A. R.; Mamdouh, Z.; Muller, W. a. Locomotion of monocytes on endothelium is a critical step during extravasation. Nat. Immunol. 2004, 5, 393-400. 